\title{
Review on Determinant of Small and Medium Enterprise Growth in Ethiopia
}

\author{
Birkinesh Gebeyehu (MSc.) \\ Department of Agricultural Ecoomics, College of Agriculture, Wolaita Sodo University, P.O.Box. 138
}

\begin{abstract}
In Ethiopia, Micro and small enterprises (MSE) serves as a source of income, employment and poverty reduction. The objective of this review is to examine determinants of MSE growth in Ethiopia. Accordingly, SME growth is mostly impacted by limited access of credit service, Lack of market linkage and information, business skill gaps, lack of sustainable training, financial constraints, poor technology, shortage of electricity and lack of reliable Power Supply, lack of infrastructure, lack of experience and high interest rate. The study recommends that the financial institutions in Ethiopia like banks and microfinance institutions should provide financial assistance through improving their borrowing procedures by lowering the interest rates and collateral and simplifying the lending systems by removing the tight borrowing regulations is vital for easier accessibility to credit by SME. Business training must be provide to the SMEs by government and non-government organization to facilitate business knowledge and give sufficient managerial and marketing skill training for MSE to change the traditional way of operating and marketing business in to the modern types of production and marketing
\end{abstract}

Keywords: SME, challenges, growth, Ethiopia

DOI: $10.7176 / \mathrm{EJBM} / 13-5-03$

Publication date:March $31^{\text {st }} 2021$

\section{INTRODUCTION}

The growth of Small and Medium Enterprises (SMEs) is a critical element in the sustainable development of developing economies. SME sector in Ethiopia has been recognized as a critical sector in the creation of employment opportunities, the generation of income and in its contribution to GDP and economic growth. Many studies explain that MSEs exert a very strong influence on economic growth in Ethiopia. According to Simen and Lara, (2009), Micro and small enterprises sector is recognized as an integral component of economic development and a crucial element in the effort of lifting countries out of poverty. Gemechu Abdissa (2016) also revealed that SMEs sector is the engine of economic growth, stimulating entrepreneurship and innovation and promoting competition and productivity and also it has vital role in unemployment reduction, equitable income distribution and import substitution and alleviating poverty in Ethiopia.

According to MSE's Development Strategy of Ethiopia (2018), the main focus of the government is creating Job opportunities through MSEs development, to reducing unemployment and alleviate poverty and enhancing MSEs to be base for industrial development in the country. The sector is crucially important to the economic and social development of the country in the sense that it generates broader job opportunities and assist to alleviate poverty and facilitates rural and urban economic linkage and boost the economy as well as promotes Entrepreneurship culture and enhance self-employment and serves as fertile ground for the emerging of Medium and Large Industries, etc.

The sector is facing many challenges, which impeded its role in the economy. For example an attempt by previous researchers (Mulu Geereeyesusu,2007; Fikadu Goshu Fufa, 2015; Belay kinati Debelo.etl, 2015; Abdulnasir Abdulmelike,2018; Wolday and Gebrehiwot, 2006) to document SME constraints and MSEs had shown little growth and unable to offer real sustainable employment and generating income, these issues still persist and as a result, Most of challenges revealed by researchers are lack of access to credit, insufficient loan size, time delay and collateral, competition, limited production/market place, lack of market for the product or service, innovation and technology and lack of skilled labor. SMEs still undergo challenges which limit the growth of them. This review, therefore, aims to evaluate the critical determinants of SME growth.

\section{Methodology}

The study used content analysis approach by reviewing more than 14 recent items of literature The study reviewed relevant articles on challenge that affect growth of micro and small enterprises. And also relevant MSEs policy documents from the Federal Micro and Small Enterprises (FMSEs) website, proclamation as well as other research documents relating to MSEs in Ethiopia were reviewed and analyzed. These efforts provided us the information necessary to arrive at some conclusion on the subject matter in Ethiopia.

\section{Literature review}

\subsection{Micro and Small Enterprises' Definition}

The definition of micro and small enterprises is may be different from country to country. The study conducted 
by Tesfaye (2014) shows that the definition of micro and small enterprises depends on the stage of economic development of the country.

According to Micro and Small Enterprises (MSEs) Development Strategy of Ethiopia, MSEs are defined on the base of total capital and working labor engaged. (FeMSEDA, 2021).

Table 1: Definition of MSE in Ethiopia

\begin{tabular}{|l|l|l|l|l|}
\hline Type of Enterprise & Sector & Human power & Working capital & \\
\hline \multirow{2}{*}{ Micro } & Industry & $<5$ & $<$ ETB 100,000 & \\
\cline { 2 - 5 } & Service & $<5$ & $<$ ETB 50,000 & $<$ ETB 1,500,000 \\
\hline \multirow{2}{*}{ Small } & Industry & $6-30$ & $<$ ETB 500,00 & \\
\cline { 2 - 5 } & Service & $6-30$ & &
\end{tabular}

Source: Federal Micro and Small Enterprise development agency (2021)

The above table showed that Micro Enterprise under the industry sector is an enterprise operates with 5 people including the owner and their total asset is not exceeding Birr 100,000. Under service sector. Micro enterprises are an enterprise operating with 5 persons including the owner of the enterprise and the values of total asset is not more than Birr 50,000. Small Enterprises in the industrial sectors are an enterprise operating with 6-30 persons and/or with a paid up capital of total asset Birr 100,000 and not exceeding Birr 1.5 million. Similarly, in the service sector, small enterprises are an enterprise operating with 6-30 persons and/or with a paid up capital of total asset Birr 50,000 and not exceeding Birr 500,000

\subsection{Role of MSEs in Ethiopia}

According to Yaregal Tilahun(2018), Fikadu Goshu (2015), Mr. Ermias Engida.etal.((2017). Micro and Small scale enterprises are generally regarded as the engine of economic growth, poverty reduction and equitable income distribution in Ethiopia. It is the second largest employment generating sector next to agriculture in Ethiopia. It have been playing an important role for achieving its development goals, to increase income and domestic saving, equitable distribution of income, better utilization of local resource, growth of large industries, achievement of economic independence, improve efficiency and production of goods and services that satisfy the basic needs of the poor

A study conducted by FDRE, (2013), for example, report that micro and small enterprises are major derivers of both employment and economic growth contributing to more than $50 \%$ to GDP and $60 \%$ to employment in developed economies, constitute less than $30 \%$ of employment and $17 \%$ of GDP in developing countries. MSEs in Ethiopia are the second largest employment generating sector next to agriculture (Habtamu et al., 2013). The MSE sector has potential to change unemployment and poverty reduction special for women.

\subsection{Factors Affecting Growth of MSEs in Ethiopia}

Various studies have been conducted in Ethiopia by describing challenging of SME that limit the growth of SME. Mulu (2007) found that the average annual growth of the surveyed six major towns in Ethiopia and $69 \%$ of these MSEs did not growth due to the problems of inadequate formal source of credit and informal network. Belay et. al (2015) conducted in Gore Towns of Ilu Aba Bora Administrative Zone reported that Lack of experience, access to capital, networking and promotion, lack of infrastructure, limited Access to Information, Reliable Power Supply, High Interest Rate, lack of market linkage, Lack of water supply service, business skill gaps, youths' negative attitude toward working in MSE and consumers perception of MSE's product as poor quality were factors that hindered MSEs growth.

According to Dagmawit and Yishak (2016) also revealed that lack of market linkage, entrepreneurship training, location of enterprise, motivation of owner, , access to finance, access to water is problem to the growth of MSEs in Durame town at Kamata Zone.

Additionally, the study conducted by Admasu, (2012), reported that most MSEs have no growth and remain at their initial level due to different internal (owner's/operator's related and/or firm's related) and external factors. The fact that the majority of firms are micro and small shows that established firms find it difficult to grow to the next higher level due to lack of an enabling environment for sustained growth.

Another study in Ethiopia conducted by Fikadu Goshu (2015) revealed that source of finance and loan term, working of entrepreneurs on the position of managerial position with low level of educational status as well as suitability and sufficiency of the work premise provided by government, lack of marketing skill of members of the business, source of raw materials, and Slack customers of the product or services threatens to undermine the growth of MSE businesses.

According to Bereket $\mathrm{T}(2017)$,In Hawassa city the major challenges facing SMEs were shortage of electricity and unscheduled power cuts, market access, lack of selling premises, Insufficient credit facility and bureaucratic working procedure .

The study conducted by Reta Lemess a.et.l( 2019) showed that MSEs in Shewa Zone of Oromia faced limited access to education and training, lack of experienced, lack of accesses to credit, lack of market linkage 
and inadequate infrastructures. These challenges controlled the enterprises to soften early rather than growing.

In Mekele city the major factors that affect growing of SMEs are lack of training, shortage of working capital, absence of appropriate technology (Zemenu and Mohammed ,2014)

\section{Conclusion and recommendation}

\subsection{Conclusions}

The purpose of this paper was to evaluate the constraints affecting the growth of SMEs in Ethiopia. The paper concludes that the major constraints that affecting the growth of SMEs listed in various studies in Ethiopia are limited access of credit service, Lack of market linkage and information, business skill gaps, lack of sustainable training, financial constraints, limited access to credit, capital constraints, poor technology, shortage of electricity and lack of reliable Power Supply, lack of infrastructure, lack of experience and high interest rate

\subsection{Recommendations}

The determinants of MSE growth identified by several researcher were varies in their severity. Majority of the problems can be solved by the combined effort of support institutions and other targeted stakeholders. Major recommendations that the reviewer recommend to reduce determinant factors that affects growth of MSE business is described as follows.

The financial institutions in Ethiopia like banks and microfinance institutions should provide financial assistance through improving their borrowing procedures by lowering the interest rates and collateral and simplifying the lending systems by removing the tight borrowing regulations is vital for easier accessibility to credit by SME.

Target government and non-government groups should offer business training continuously to SMEs in different regions of Ethiopia to enable them to gain new business knowledge and to change their way of thinking.

The another important concern is giving sufficient managerial and marketing skill training and experience sharing for MSE to enhance their marketing skills and to change the traditional way of operating and marketing business in to the modern types of production and marketing.

Different stakeholders like Federal, regional and zonal government should give attention to the improvement of infrastructures such as roads, electricity, pure water and information dissemination.

Generally hard work is expected from government and MSE leaders to change attitude of community toward MSE sector and their product at all to improve and sustain MSE .

Future researchers should focus on how these issues affect SME growth individually by conducting primary data collection and analysis. It will be interesting to conduct a comparative study on the growth impediments to SMEs in developed and developing nations.

References

Abdulnasir Abdulmelike, Semeneh Bese (phd), Gezahegn Sime, Fasil Ejigu, Mohammedhussen Mama(2018). Challenges and Opportunities of MSEs in Ethiopia: A Review Paper. journal of Economics and Sustainable Development Vol.9, No.19.

Adimasu Abera (2012). Factors Affecting the performance of Micro and Small Enterprise in Areda and Lideta Sub-city, Addis Ababa. Unpublished Master's Thesis

Belay kinati, AsmeraTeshome and TekalignMinalu. 2015. Factors Affecting Developments of Micro and Small Enterprises. The case of Mettu, Hurumu, Bedelle and Gore Towns of Ilu Aba Bora Administrative Zone, International Journal of Scientific and Research Publications, vol. 5(1).

Bereket Teklehimanot. (2017). The socio-economic impacts of micro and small enterprises: A case study of metal and woodwork enterprise in Meneharia sub-city, Hawassa, Ethiopia . Masters Thesis, Stockholms University.

Dagmawit A, and Yishak G, (2016). Determinants of Micro and Small Enterprises growth: the case of Durame Town, Kembata Tembaro Zone, Southern Nations and Nationalities and Peoples Region, Ethiopia. International Journal of Business and Economics Research 5: 161175. Davidsson, P. and Wiklund, J. (2000),

Ermias, E. Mekdim, D. Ibrahim, W. Saba Y. and Feiruz. Y. 2017. The role of micro and small enterprises in reducing unemployment and poverty in Ethiopia: number 165.

FDRE. 2013. Federal Democratic Republic of Ethiopia Ministry of urban development and construction, Survey on Micro and Small Enterprises (MSEs) in Selected Major Cities of Ethiopia.

Federal Micro and Small Enterprise development agency (2021). Implementation, success and challenges of Micro and Small Enterprises (MSEs) development in Ethiopia.

FikaduGoshu. 2015. Determinants of Micro and Small Enterprises Growth in Ethiopia: The Case of Nekemte Town of Oromia Region, Ethiopia, European Journal of Business and Management, vol. 7 (13).

Gemechu Abdissa,2019. Factors Affecting Performance of Micro and Small Enterprises in South West Ethiopia: The Case of Bench Maji, Sheka, and Kefa Zones. Global Journal of Management and Business Research. 
Habtamu Tefera, AregawiGebremichael and NigusAbera. 2013. Growth Determinants of Micro and Small Enterprises: Evidence from Northern Ethiopia. Journal of Economics and Sustainable Development, 4(9).

Mulu G. (2007). Growth of Micro-Enterprises: Empirical evidence from Ethiopia. Ethiopian Development Research Institute (EDRI), Ethiopia

Reta Lemessa, Sori Tefera and Senahara Korsa,2019. Factors Influencing Growth of Micro and Small Enterprises: case of Ambo, Bako, Gedo and Ginchi Towns Oromia, Ethiopia. Journal of Science and Sustainable Development (JSSD), 7(1), 32-42

Simeon, N. and Lara, G. (2009) 'Small Firm Growth in Developing Countries', World Development, vol. 37, no. 9 , p. $1453-1464$

Tesfaye Tegegn. 2014. The role of micro and small enterprises in reducing youth unemployment: the case of Meserak TVET College graduates in Addis Ababa city administration.

Wolday Amha, Gebrehiwot Ageba, (2006) "Business development services (BDS) in Ethiopia: Status, prospects and challenges in the micro and small Enterprises.

Yaregal Tilahun Geremewe, (2018). "The Role of Micro and Small Enterprises for Poverty Alleviation" International Journal of Research Studies in Agricultural Sciences (IJRSAS), 4(12), pp.38-47,

ZemenuAynadis and Mohammed Nure. 2014. Determinants of Growth of Micro and Small Enterprises in Ethiopia: A Case of MSEs in Mekelle City, Tigray. International Journal of Advance Research in Computer Science and Management Studies, 2 (6), p.149-157. 